2

I N S A N

\title{
Hubungan antara Harapan (Hope) dengan Resiliensi terhadap Istri yang Mengalami Involuntary Childless
}

\author{
RUSLIYANTI MUHARROMAH \& WIWIN HENDRIANI* \\ Departemen Psikologi Pendidikan dan Perkembangan, Fakultas Psikologi Universitas Airlangga
}

\begin{abstract}
ABSTRAK
Penelitian ini bertujuan untuk melihat ada atau tidaknya hubungan antara harapan (hope) dengan resiliensi pada istri yang mengalami involuntary childless. Penelitian ini ditujukan untuk istri involuntary childless yang memiliki usia pernikahan 5 tahun atau lebih. Jumlah subjek dalam penelitian adalah 66 orang. Alat ukur yang digunakan pada penelitian ini adalah skala harapan State Hope Scale (SHS) berjumlah 6 aitem $(\alpha=0,760)$, skala resiliensi Resilient Quotient (RQ) yang telah ditranslasi oleh berjumlah 32 aitem $(\alpha=0,789)$. Berdasarkan hasil analisis yang dilakukan, diperoleh hubungan yang positif $(\mathrm{R}=0,280, p<0,05)$ antara harapan (hope) dengan resiliensi pada istri yang mengalami involuntary childless. Hal tersebut dapat diartikan bahwa semakin tinggi tingkat harapan yang dimiliki, maka semakin tinggi pula resiliensi yang dimilikinya, begitu pula sebaliknya.
\end{abstract}

Kata kunci: harapan, involuntary childless, resiliensi

\begin{abstract}
This study aimed to study should there be any relationship between hope and resilience on involuntary childless wife. The participants of the study were involuntary childless wives whose marriage age was 5 years or more. There were 66 participants. The measuring instrument of hope was Snyder's State Hope Scale (1996) with 6 items $(\alpha=760)$. The measuring instrument of resilience was Reivich \& Shatte's Resilient Quotient (2002) containing 32 translated items $(\alpha=0.789)$. The data analysis result confirmed that there was a positive correlation $(\mathrm{R}=0.280, \mathrm{p}<0.05)$ between hope and resilience on involuntary childless wives. The results showed that higher level of hope signifies a higher level of resilience and vice versa.
\end{abstract}

Key words: hope, involuntary childless, resilience

INSAN Jurnal Psikologi dan Kesehatan Mental, 2019, Vol. 4(1), 19-27, doi: 10.20473/jpkm.v4i12019.19-27 Dikirimkan: 16 Oktober 2019 Diterima: 10 Desember 2019 Diterbitkan: 27 Februari 2020

Editor: Dewi Syarifah

*Alamat korespondensi: Fakultas Psikologi Universitas Airlangga, Jalan Airlangga 4-6 Surabaya 60286. Pos-el: wiwin.hendriani@psikologi.unair.ac.id

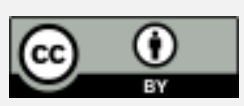

Naskah ini merupakan naskah dengan akses terbuka dibawah ketentuan the Creative Common Attribution License (http://creativecommons.org/licenses/by/4.0), sehingga penggunaan, distribusi, reproduksi dalam media apapun atas artikel ini tidak dibatasi, selama sumber aslinya disitir dengan baik. 


\section{P E N D A H U L U A N}

Pernikahan merupakan sebuah ikatan komitmen antara seorang pria dan wanita untuk dapat menyatukan kehidupan dalam jangka waktu yang lama, sehingga mereka akan menjalankan kehidupan sesuai dengan hak dan kewajiban yang telah disepakati untuk mendapatkan kehidupan sesuai dengan hak dan kewajiban yang telah disepakati untuk mendapatkan kehidupan yang layak, sejahtera, harmonis dan juga mendapatkan keturunan (Bachtiar, 2001). Salah satu dari tujuan utama dalam menikah adalah memiliki anak dan memperoleh pengakuan secara langsung dari masyarakat mengenai pengasuhan (Bird, 1994). Kehadiran anak kerap dianggap menjadi tanda kesejahteraan pernikahan serta menjadi harapan pada hubungan kedua orang tua kedepannya seiring tumbuh kembang anak (Lestari, 2012). Menurut Dobos, dkk (1999) menjelaskan mengenai filosofi anak, beberapa diantaranya adalah anak akan memperluas jati diri orang tua, anak dapat menjadi penyelamat bertahannya perkawinan yang hampir hancur, anak sebagai pendamping orang tua ketika salah satu dari mereka telah meninggal dunia, dan anak berfungsi sebagai teman hidup dan memberikan rasa aman. Namun, tidak semua pasangan suami istri mampu mewujudkan keinginan mereka untuk memiliki anak (Hidayah, 2010). Terkadang keadaan tertentu membuat pasangan suami istri mengalami kegagalan ataupun penundaan secara tidak sengaja untuk mewujudkan keinginan tersebut (Laksmi \& Kustanti, 2017).

Veevers (1986) menjelaskan bahwa sebuah keadaan dimana pasangan memiliki keinginan untuk memiliki anak tetapi mereka masih belum memilikinya secara tidak disengaja disebut dengan Involuntary childless (Miall, 1986). Sedangkan menurut sudut pandang psikologi sosial, involuntary childless adalah keadaan pasangan yang belum memiliki anak dalam lingkup waktu tertentu tidak hanya dilihat dari kondisi biologis (fertil atau infertil), melainkan keinginan psikologis untuk memiliki anak tetapi tidak mampu untuk mendapatkannya (Ulfah, 2014). Laksmi dan Kustanti (2017) menjelaskan bahwa penyebab dari pasangan yang mengalami Involuntary Childles bermacam- macam seperti adanya infertilitas pada kedua atau salah satu pasangan, pernikahan dini sehingga berakhir pada penundaan untuk memiliki anak, kegagalan mengandung tanpa sebab, dan juga istri yang bekerja secara penuh waktu (Laksmi \& Kustanti, 2017) .

Penelitian yang dilakukan oleh Nasrabad, dkk. (2011) mengenai peningkatan childlessness yang ada di Iran, membawakan hasil bahwa dari 13,2\% istri yang tidak memiliki anak (sekitar 11.324 subjek), sebanyak 4,5\% mengalami involuntary childless. Setelah itu, dari 4,5\% istri dengan involuntary childless, ditemukan $2 \%$ dari mereka yang mengalami infertilitas, histeroktomi (pengangkatan rahim), dan penyakit. Sementara itu, 2,5\% lainnya berkeinginan untuk memiliki anak dan masih mencoba untuk memiliki anak (Nasrabad dkk., 2011). Selain itu, terdapat studi longitudinal yang dilakukan oleh Australian Institute (2000) tentang efek dari perubahan hubungan dengan pasangan karena adanya anak. Setiap 10 tahun sekali (awal survei tahun 1981, survei lanjutan tahun 1990) responden mengisi kuisioner yang terdapat pertanyaan mengenai keinginan untuk memiliki anak. Pada survei kedua, didapatkan data dari pasangan yang belum memiliki anak memiliki prevalensi bahwa terdapat $28 \%$ responden yang belum memiliki anak dan masih ingin memiliki anak, 16.7\% responden yang dulunya tidak ingin memiliki anak menjawab bahwa mereka ingin memiliki anak di survei yang kedua, 28.2\% responden yang dulunya menjawab tidak yakin tetapi pada survei yang kedua mereka menjawab ingin memiliki anak (Qu dkk., 2000). Di sisi lain, sekitar 10\% dari responden wanita dan 20\% dari responden pria yang belum memiliki anak dan merupakan golongan tua dalam survei (40- 44 tahun) juga masih memiliki keinginan untuk memiliki anak (Qu dkk., 2000).

Hasil penelitian yang dilakukan oleh Azizah (2016) menjelaskan bahwa istri yang mengalami involuntary childless rentan terkena masalah psikologis seperti stres, depresi, perasaan rendah diri,

INSAN Jurnal Psikologi dan Kesehatan Mental

2019, Vol. 4(1), 19-27

doi: 10.20473/jpkm.v4i12019.19-27

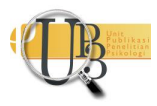


dan pola berpikir negatif. Hal tersebut dikarenakan sebagian besar istri involuntary childless dihadapkan pada masyarakat di lingkungan sekitar mereka yang seringkali menanyakan sudah hamil atau belum, ditambah dengan pernyataan dari keluarga seperti orang tua dan mertua yang selalu memberi pesan tersirat bahwa mereka ingin memiliki cucu (Azizah, 2016). Dampak lain dari involuntary childless terutama pada istri adalah adanya perasaan tidak berharga, melemahkan hubungan antara pasangan, adanya pikiran bahwa hubungan pernikahan yang telah dibangun tidak berarti, meningkatkan distres, sering merasa putus asa serta kehilangan harapan (Monach, 2003). Pernyataan tersebut didukung oleh hasil penelitian yang dilakukan oleh Omu (2010) yang menyatakan bahwa pasangan yang mengalami infertil mengalami beberapa reaksi emosional yaitu kecemasan berlebihan pada wanita sebesar $12.7 \%$ sedangkan pada pria $6 \%$, adanya penurunan libido sebesar $6,7 \%$ pada wanita sedangkan pada pria sebesar $29,39 \%$, serta depresi pada wanita $5.2 \%$ sedangkan pada laki- laki sebesar 14,9\% (Omu, 2010). Peneliti juga telah melakukan wawancara pendahuluan untuk mencari data awal pada 2 orang partisipan (DS dan NA) untuk memperjelas data dan pernyataan diatas.

Hasil yang didapat dari 2 partisipan tersebut adalah mereka cenderung merasa kecewa dengan diri mereka, kecewa dengan keadaan yang mereka alami sehingga mereka menutup diri dari lingkungan sekitar. Hasil wawancara juga menyebutkan bahwa kedua partisipan merasa hubungan mereka dengan suami semakin renggang ditambah lagi mereka merasa tertekan karena berbagai macam usaha telah dilakukan tetapi belum membuahkan hasil. Selain itu, menurut Monach (2003) dalam bukunya menjelaskan bahwa salah satu hal yang memungkinkan untuk terjadi pada pasangan involuntary childless adalah perceraian. Terdapat satu dari empat pasangan yang menikah adalah berusia 45 tahun dan kebanyakan dari mereka tidak memiliki anak (Monach, 2003). Pernyataan tersebut didukung oleh jurnal putusan perkara (Chintia T.S., 2015) yang membahas mengenai proses perceraian pasangan yang berakar dari ketidakhadiran anak diantara mereka dan pada akhirnya menyebabkan konflik yang semakin besar, ketidak cocokan antara suami dan istri semakin besar, seringnya terjadi perselisihan dan pertengkaran karena belum memiliki anak, serta sikap orang tua yang sering ikut campur dalam permasalahan rumah tangga yang dirasa tidak ada harapan untuk hidup rukun kembali (Chintia, 2015).

Akan tetapi dari kasus- kasus yang telah disebutkan, masih ada beberapa pasangan yang mampu beradaptasi secara baik meskipun mereka mengalami involuntary childless (Monach, 2003). Peneliti melakukan penelitian pendahuluan berupa survei mengenai seberapa dekat hubungan pasangan yang mengalami involuntary childless. Partisipan yang berkontribusi untuk mengisi survei sebanyak 51 orang istri yang mengalami involuntary childless yang memiliki usia pernikahan dengan rentang 5 sampai 25 tahun. Dari 51 partisipan, sebanyak 51\% atau 26 partisipan merasa hubungan mereka sangat baik dan romantis, sebaliknya hanya $11 \%$ atau 6 partisipan merasa hubungan pernikahan mereka tidak baik. Sebagian besar partisipan yang merasa hubungan dengan suaminya sangat baik dan romantis menuliskan bahwa hubungan mereka masih seperti rasa pacaran, masih menyempatkan waktu untuk quality time bersama di akhir Minggu dan yang lainnya. Selain itu, sebanyak 60.8\% partisipan menjawab santai dan apa adanya mengenai pertanyaan kapan memiliki anak, 23.5\% partisipan memilih untuk mengabaikan pertanyaan dan mencari topik baru, dan $11.8 \%$ partisipan memilih untuk diam. Hasil tersebut cukup menggambarkan masih ada pasangan- pasangan yang belum memiliki anak dengan usia pernikahan 5 sampai 25 tahun tetapi mereka masih memiliki hubungan yang dekat dan romantis.

Ketika istri dengan involuntary childless menghadapi sebuah situasi yang tidak dapat diubah, terutama dengan masalah ketidakhadiran anak yang cenderung sulit, mereka akan menerima, pasrah, dan sabar dengan tetap fokus pada masa depan (Pandanwati, 2012). Istri dengan involuntary childless yang

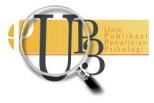


cenderung mampu untuk beradaptasi dengan keadaan yang baru, menjalani hari-harinya kembali seperti biasa serta menerima keadaan dengan lapang dada setelah mengalami peristiwa yang tidak menguntungkan merupakan individu yang mencapai resiliensinya. Resiliensi adalah suatu usaha dari dalam diri seseorang untuk terampil dalam mengatasi beban dan resiko kehidupan seperti peristiwa yang membuat trauma dan stres serta keadaan- keadaan yang sulit dengan cara bertahan, bangkit, serta menyesuaikan keadaan (Reivich \& Shatte, 2002).

Istri dengan involuntary childless akan mengalami berbagai macam stressor yang berpengaruh pada kondisi psikologis mereka. Sebelum mereka mencapai resiliensinya, mereka butuh beradaptasi, menerima dengan lapang dada, serta berdamai dengan keadaan dan lingkungan sebagai proses pemulihan untuk bounce back ke keadaan awal mereka. Resiliensi memiliki dua faktor utama. Faktor tersebut adalah hal yang mempengaruhi semakin tinggi atau rendahnya tingkat resiliensi yang dimiliki seseorang, yaitu faktor resiko dan faktor protektif. Faktor resiko yang terjadi pada istri dengan involuntary childless misalnya seperti adanya konflik dengan pasangan, keluarga bahkan dengan diri mereka sendiri. Faktor protektif yang berpengaruh pada resiliensi individu dengan involuntary childless antara lain perasaan kebersamaan yang kuat, self control yang tinggi, regulasi emosi, evaluasi diri, keyakinan pada diri sendiri jika mampu melewati situasi traumatis, optimis, dan pengharapan positif (Pandanwati, 2012). Individu akan meraih masa resiliensinya ketika mereka cenderung mengarahkan dirinya pada pengambilan keputusan serta penyelesaian masalah yang bertujuan pada suatu perubahan, sehingga individu cenderung lebih kuat dan memiliki harapan akan masa depan (Reivich \& Shatte, 2002). Kumpfer (1999) menjelaskan bahwa individu yang memiliki kualitas harapan yang baik akan cenderung gigih dan memiliki tekad yang besar dimana kedua faktor tersebut adalah hal yang mempengaruhi resiliensi individu (Malik, 2013).

Harapan (hope) merupakan sebuah keinginan serta keyakinan dalam kehidupan individu yang dapat membuat kualitas hidup individu menjadi lebih baik serta ditambah oleh adanya motivasi untuk dapat meraih harapan tersebut (Snyder \& Lopez, 2002). Permasalahan yang dialami oleh istri dengan involuntary childless adalah kemampuan untuk mendapatkan apa yang diharapkannya yaitu memiliki anak (Khoiri, 2017). Istri dengan keadaan seperti ini akan berusaha dan termotivasi untuk mencoba semua usaha agar dapat menjadi orang tua. Selain itu, perkembangan teknologi mengenai fertilitas semakin canggih dan modern juga telah memberikan harapan lebih besar kepada istri involuntary childless untuk mendapatkan momongan (Juu \& Chen, 2006). Individu akan terjebak kedalam situasi yang tidak menguntungkan jika mereka mengalami involuntary childless. Beberapa dari mereka akan mampu untuk keluar dari situasi tersebut dan kemudian secara psikologis mereka berangsur pulih berkat kemampuan resiliensinya yang baik. Pada hasil penelitian yang dilakukan oleh Pandanwati (2012), pasangan yang tidak memiliki anak mencapai resiliensinya karena mereka memiliki pengharapan positif dan keyakinan untuk dapat menghadapi tantangan. Pernyataan tersebut juga didukung oleh hasil wawancara pendahuluan yang telah dilakukan peneliti, berikut kutipannya:

“Terus kalo mbak adanya inisiatif buat move on dan mencari kegiatan karena mbak pengen nggak sedih lagi, mbak berharap seenggaknya nggak nangis nangis lagi nggak menutup diri lagi gitu.

Ditambah lagi kan mbak juga masih pengen punya anak," (DS200719/48)

Kutipan wawancara diatas menjelaskan tentang keinginan subjek DS untuk move on dan melanjutkan kehidupannya adalah tidak ingin terjebak dalam situasi tidak menguntungkan terus menerus dan ada harapan untuk memiliki anak.

Berdasarkan beberapa uraian serta asumsi yang telah dijelaskan sebelumnya diketahui bahwa resiliensi adalah upaya dari individu khususnya wanita yang mengalami involuntary childless untuk

INSAN Jurnal Psikologi dan Kesehatan Mental

2019, Vol. 4(1), 19-27

doi: 10.20473/jpkm.v4i12019.19-27

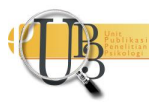


keluar dari masa sulitnya, dimana di dalamnya terdapat pula harapan yang memungkinkan individu untuk meraih kualitas hidup yang lebih baik, harapan untuk memiliki anak misalnya. Untuk itu penelitian yang akan dilakukan adalah mencari apakah ada hubungan antara harapan (hope) dengan resiliensi istri yang mengalami involuntary childless

\section{MET ODE}

Variabel x pada penelitian ini adalah harapan (hope), yaitu proses dari tercapainya suatu tujuan (goals), dimana terdapat motivasi untuk melakukan sesuatu pada hal tertentu untuk mencapai tujuan tersebut (agency), serta proses untuk mencari cara agar tujuan tersebut segera tercapai (pathways) (Snyder dkk., 1991). Harapan memiliki 3 dimensi utama yaitu goals, agency thinking, dan pathways thinking. Sedangkan variabel y pada penelitian ini adalah resiliensi, yaitu suatu usaha dari dalam diri seseorang untuk terampil dalam mengatasi beban dan resiko kehidupan seperti peristiwa yang membuat trauma dan stres serta keadaan-keadaan yang sulit dengan cara bertahan, bangkit, serta menyesuaikan keadaan (Reivich \& Shatte, 2002).

Penelitian ini menggunakan pendekatan kuantitatif (eksplanatori) dengan menyebarkan kuesioner secara online dan offline. Penelitian ini menggunakan purposive sampling dengan kriteria subjek adalah istri yang mengalami involuntary childless dengan usia pernikahan minimal 5 tahun. Teknik analisis data yang digunakan adalah uji korelasi Spearman's Rho Correlations Test. Sehingga dapat diketahui ada atau tidaknya hubungan antara harapan (hope) dengan resiliensi pada istri yang mengalami involuntary childless.

Instrumen yang digunakan pada penelitian ini adalah State Hope Scale milik Snyder (1996) yang berisi 6 item dengan nilai reliabilitas 0,760. Untuk variabel resiliensi menggunakan instrumen Resilience Quotient milik Reivich \& Shatte (2002) yang telah ditranslasikan oleh Mardiani (2012) berisi 32 aitem dengan nilai reliabilitas 0,889 .

\section{HAS IL PENELITIAN}

Subjek yang berpartisipasi pada penelitian ini adalah istri yang mengalami involuntary childless dengan usia pernikahan minimal 5 tahun sebanyak 66 orang. Pada rincian usia, subjek didominasi oleh kelompok usia 21-30 tahun. Adapun jumlah istri dengan usia 21-30 tahun yang menjadi subjek dalam penelitian ini sebanyak 26 orang (39,4\%), usia 31-40 tahun sebanyak 22 orang (33,3\%), usia $41-50$ tahun sebanyak 15 orang (22,7\%), dan subjek dengan usia diatas 50 tahun sebanyak 3 orang $(4,5 \%)$. Selain itu, pada perincian usia pernikahan subjek didominasi oleh istri yang memiliki usia pernikahan dengan range umur 5-10 tahun. Adapun jumlah subjek yang memiliki usia pernikahan 5-10 tahun sebanyak 38 orang (57,6\%), memiliki usia pernikahan 11-15 tahun sebanyak 12 orang (18,2\%), memiliki usia pernikahan 16-20 tahun sebanyak 10 orang $(15,2 \%)$, serta yang memiliki usia pernikahan lebih dari 20 tahun sebanyak 6 orang $(9,1 \%)$.

Dikarenakan distribusi data pada kedua variabel tidak normal, maka teknik analisis yang digunakan untuk menguji kedua hubungan antar variabel adalah teknik analisis non parametrik, yaitu dengan Spearman's rho. Harapan (hope) dan variabel resiliensi berkorelasi positif, namun lemah $(\rho(66)=0.280$, $p=0.023$ ). Arah hubungan dari kedua variabel ini adalah positif yang berarti semakin tinggi harapan yang dimiliki individu, maka semakin tinggi pula resiliensi yang dimiliki individu dan juga sebaliknya. 


\section{I S K U S I}

Nilai rendah dalam korelasi ini mungkin saja disebabkan oleh subjek yang dominan memiliki usia pernikahan 5-10 tahun. Dimana menurut Callan (1999), istri involuntary childless akan memiliki kualitas kesejahteraan yang rendah, berpikir bahwa hidupnya kurang menarik serta akan merasa kesepian ketika mereka menginjak usia pernikahan ke lima tahun (Ulfah, 2014). Pernyataan tersebut didukung oleh data hasil kategorisasi subjek pada variabel resiliensi, dari data tersebut disimpulkan bahwa subjek dalam penelitian didominasi oleh individu yang memiliki tingkatan resiliensi yang sangat rendah yaitu sebanyak 23 orang $(34,8 \%)$.

Hasil penelitian ini sejalan dengan penelitian yang dilakukan oleh Cathlin (2018) yang juga membahas mengenai harapan dan resiliensi dengan konteks yang berbeda yaitu istri yang pernah mengalami abortus spontan. Hasil dari penelitian tersebut menyatakan bahwa adanya hubungan yang positif antara harapan dan resiliensi, dimana penelitian tersebut menguji hubungan tiap dimensi dari harapan dengan variabel resiliensi yang mendapatkan hasil bahwa dimensi pertama yaitu willpower (agency thinking) mendapatkan hasil korelasi sebesar 0,000 dengan tingkat korelasi 0,512 yang berarti sedang. Selain itu, dimensi kedua yaitu waypower (pathway thinking) mendapatkan hasil korelasi sebesar 0,000 dan memiliki tingkat korelasi 0,289 yang berarti rendah.

Selain itu, hasil yang didapat sejalan dengan teori milik Bailey \& Snyder (dalam Cathlin, 2018) yang menyatakan bahwa harapan merupakan salah satu faktor protektif dari resiliensi yang memiliki fungsi untuk mengurangi tekanan yang dihadapi oleh wanita dewasa yang mengalami involuntary childless. Wanita dewasa dengan tingkatan harapan yang tinggi akan cenderung memiliki tingkat depresi dan luka (impairment) yang lebih rendah dibandingkan dengan wanita yang memiliki tingkatan harapan rendah (Snyder dkk., 1991). Harapan membuat individu, khususnya istri yang mengalami involuntary childless dapat bertahan menghadapi berbagai macam tekanan eksternal maupun internal. Kemampuan bertahan dari kejadian- kejadian traumatis yang dialami istri involuntary childless inilah yang dinamakan resiliensi. Ketika resiliensi diperkuat oleh faktor protektif, wanita dewasa mampu untuk mengidentifikasi dan memahami resiko yang akan terjadi serta mampu untuk menemukan tujuan dan makna hidupnya (Reivich \& Shatte, 2002). Salah satu faktor protektif dari resiliensi adalah adanya harapan (Malik, 2013).

Selain itu, penelitian ini juga sejalan dengan penelitian yang dilakukan oleh Ong, dkk (2006) yang menyatakan bahwa harapan menjadi salah satu sumber dari resiliensi. Istri yang mengalami involuntary childless akan selalu berusaha untuk mereduksi stres yang dialaminya jika ia memiliki harapan yang tinggi dalam dirinya. Mereka akan memunculkan emosi positif seperti rasa optimis untuk memecahkan masalah yang sedang dihadapi dengan tujuan untuk meraih kualitas kehidupan seperti sebelumnya atau bahkan ingin mencapai kualitas kehidupan yang lebih baik. Harapan merupakan salah satu dari sumber resiliensi baik dari dalam atau luar individu, harapan masuk kedalam berbagai macam cara dan strategi untuk dapat mengurangi stressor yang muncul di kehidupan sehari- hari (Ong dkk., 2006).

Berdasarkan hasil kategorisasi subjek pada hasil penelitian dapat diketahui bahwa jumlah istri involuntary childless dengan kategori harapan sangat rendah sebanyak 6 orang, subjek dengan kategori rendah sebanyak 11 orang, subjek dengan kategori sedang sebanyak 23 orang, subjek dengan kategori tinggi sebanyak 21 orang, dan subjek dengan kategori sangat tinggi sebanyak 5 orang. Dari data tersebut dapat disimpulkan bahwa dalam penelitian ini subjek yang mendominasi adalah subjek dengan kategori harapan sedang dan tinggi. Permasalahan yang dialami oleh istri dengan involuntary childless adalah kemampuan untuk mendapatkan apa yang diharapkannya yaitu memiliki anak (Khoiri,

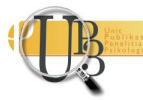


2017). Istri dengan keadaan seperti ini akan berusaha dan termotivasi untuk mencoba semua usaha agar dapat menjadi orang tua. Selain itu, perkembangan teknologi mengenai fertilitas semakin canggih dan modern juga telah memberikan harapan lebih besar kepada istri involuntary childless untuk mendapatkan momongan (Juu \& Chen, 2006).

Jumlah istri involuntary childless dengan kategorisasi harapan yang sedang dan tinggi memang cukup banyak, tetapi peneliti juga tidak dapat mengesampingkan beberapa subjek dengan kategorisasi harapan yang rendah dan sangat rendah. Sebanyak 6 orang subjek memiliki harapan yang sangat rendah dan sebanyak 11 orang memiliki harapan yang rendah. Data tersebut menunjukkan kemungkinan bahwa masih ada beberapa istri involuntary childless yang belum mencapai masa resiliensinya. Oleh karena itu, perlu memperhatikan rendahnya harapan pada subjek karena harapan adalah salah satu faktor protektif dari terbentuknya resiliensi (Malik, 2013).

Selain itu, dilihat dari hasil kategorisasi variabel resiliensi, dapat diketahui bahwa istri involuntary childless yang berkontribusi pada penelitian ini dengan kategorisasi sangat rendah sebanyak 23 orang, subjek dengan kategorisasi rendah sebanyak 11 orang, subjek dengan kategorisasi sedang sebanyak 10 orang, subjek dengan kategorisasi tinggi sebanyak 4 orang, dan subjek dengan kategorisasi sangat tinggi sebanyak 18 orang. Dari data yang telah disebutkan, dapat diketahui bahwa pada penelitian ini, subjek yang mendominasi adalah istri involuntary childless yang memiliki tingkat resiliensi yang sangat rendah. Hal tersebut menunjukkan bahwa terdapat istri involuntary childless yang kurang resilien. Hal tersebut mungkin saja dipengaruhi juga oleh stigma negatif yang ada di masyarakat. Pada sebagian besar wilayah Asia, wanita involuntary childless akan mengalami stigma yang negatif dari masyarakat dan menghadapi konsekuensi pribadi dan sosial yang cukup serius (P.V \& Moli, 2012). Dari pernyataan tersebut menurut Frederickson (2002) mungkin beberapa istri involuntary childless masih terpaku pada stigma yang ada sehingga akan sulit bagi mereka untuk keluar dari masa- masa tidak menguntungkan. Individu yang kurang resilien akan sulit untuk meraih well-being-nya (Purwanti, 2018).

\section{S I M P U L A N}

Penelitian ini memiliki kesimpulan bahwa terdapat korelasi positif antara harapan (hope) dan resiliensi pada istri yang mengalami involuntary childless. Berarti semakin tinggi harapan yang dimiliki maka semakin tinggi pula resiliensi yang dimiliki pada istri yang mengalami involuntary childless. Begitu pula sebaliknya, semakin rendah tingkat harapan yang dimiliki maka semakin rendah pula tingkat resiliensi yang dimiliki oleh istri yang mengalami involuntary childless.

Saran untuk peneliti selanjutnya diharapkan untuk menambah jumlah partisipan dan memastikan bahwa data variatif, karena data yang variatif akan berguna untuk menambah informasi mengenai subjek itu sendiri dalam penelitian. Memastikan dan menyesuaikan lagi karakteristik subjek dengan variabel-variabel yang akan diteliti. Penelitian selanjutnya juga dapat meneliti mengenai istri yang mengalami voluntary childless, yaitu ketidakhadiran anak karena disengaja seperti menunda untuk memiliki anak secara disengaja.

Bagi para suami dan keluarga yang memiliki istri atau anggota keluarga involuntary childless, diharapkan untuk saling mendukung serta membangun lingkungan yang positif sehingga psikologis istri involuntary childless serta keluarga akan tetap sehat. Suami dan keluarga diharapkan selalu memberikan dorongan berupa kasih sayang serta motivasi dan semangat agar harapan yang dimiliki istri involuntary childless akan meningkat diiringi dengan kemampuan resiliensi yang baik pula. 


\section{U C A P A N T ERIMA KASIH}

Ucapan terimakasih diucapkan kepada Fakultas Psikologi UNAIR, ibu Wiwin Hendriani selaku dosen pembimbing serta seluruh pihak yang telah berkontribusi pada penelitian ini.

\section{DEKLARASI POTENSI TERJADINYA KONFLIK KEPENTINGAN}

Rusliyanti Muharromah dan Wiwin Hendriani tidak bekerja, menjadi konsultan, memiliki saham, atau menerima dana dari perusahaan atau organisasi manapun yang akan mengambil untung dari naskah ini, dan telah mengungkapkan bahwa ia tidak memiliki afiliasi selain yang telah disebut diatas.

\section{PUSTAKA ACUAN}

Azizah, N. (2016). Problem Psikologis Istri yang Belum Dikarunai Anak di Desa Sridadi Kecamatan Sirampog Kabupaten Brebes. Purwokerto: Fakultas Dakwah dan Komunikasi Institut Agama Islam Negeri Purwokerto.

Bachtiar, A. (2001). Menikahlah, Maka Engkau Akan Bahagia. Jogjakarta: Saujana.

Bird, G. K. (1994). Families and intimate relationship. New York: Mc- Graw Hill Inc.

Chintia T.S., R. S. (2015). Perceraian Karena Tidak Memiliki Keturunan dan Campur Tangan Orang Tua (Studi Putusan Perkara Nomor 1294/Pdt.G/2011/PA.Mlg Korelasinya dengan Pasal 19 huruf f Peraturan Pemerintah Republik Indonesia Nomor 9 Tahun 1975). Jurnal Fakultas Hukum Universitas Brawijaya.

Hidayah, N. (2010). Nilai Anak, Stress Infertilitas dan Kepuasan Perkawinan pada Wanita yang Mengalami Infertilitas. Fakultas Psikologi Universitas Ahmad Dahlan.

Juu, S. T., \& Chen, Y. C. (2006). Transforming Hope: The LIved Experience of Infertile WOmen Who Terminated Treatment After in Vitro Fertilization Failure. Journal of Nursing Research, 14.

Khoiri, Q. (2017). Harapan (Hope) untuk memiliki anak pada wanita dewasa awal yang mengalami Involuntary Childless. Skripsi Universitas Airlangga, 1- 10.

Laksmi, V. A., \& Kustanti, E. R. (2017). Hubungan antara dukungan sosial suami dengan resiliensi istri yang mengalami Involuntary Childless. Jurnal Empati, 431- 435.

Lestari, S. (2012). Psikologi Keluarga: Penanaman nilai dan penanganan konflik dalam keluarga. Jakarta: Kencana Prenada Media Group.

Malik, A. (2013). Efficacy, Hope, Optimism and Resilience at Workplace - Positive Organizational Behavior . International Journal of Scientific and Research Publications, 1- 4.

Miall, C. E. (1986). The Stigma of Involuntary Childlessness. Social Problems, 33.

Monach, J. H. (2003). Childless: No Choice. The Experience of Involuntary Childlessness. New York: Taylor \& Francis e- Library.

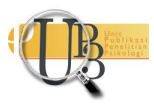


Nasrabad, H. B., Shavazi, M. J., \& Moeinifar, M. (2011). Are we facing a dramatic increase in infertility and involuntary childlessness that lead to lower fertility?

Omu, F. (2010). Emotional reaction to diagnosis of infertility in Kuwait and successful clients' perception of nurses' role during treatment. Retrieved from http://www.biomedcentral.com/14726955/9/5 (diakses pada tanggal 25 November 2018)

Ong, A. D., Edwards, L. M., \& Bergeman, C. (2006). Hope as a source of resilience in later adulthood. Personality and Individual Differences.

P.V, A., \& Moli, G. (2012). Childlessness Among Women in India. Health and Population- Perspectives and Issues, 114- 131.

Pandanwati, K. \&. (2012). Resiliensi Keluarga Pada Pasangan Dewasa Madya yang Tidak Memiliki Anak . Jurnal Psikologi Universitas Airlangga.

Purwanti, D. A. (2018). Hubungan Antara Resiliensi dan Psychological Wellbeing Pada Ibu yang Memiliki Anak dengan Autis. Jurnal Empati, 284- 285.

Qu, L., Weston, R., \& Kilmartin, C. (2000). Effects of Changing Personal Relationship on Decisions About Having Children. Australian Institute of Family Studies, 14- 19.

Reivich, K., \& Shatte, A. (2002). The Resilience Factor: 7 Keys to Finding Your Inner Strength and Overcoming Life's Hurdles. Three Rivers Press.

Snyder, C. R., Irving, L. M., \& Anderson, J. R. (1991). Hope and Health.

Snyder, C., \& Lopez, S. J. (2002). Handbook of Psositive Psychology. In C. Snyder, K.L. Rand, \& D.R. Sigmon, Hope Theory. New York: University Press, Inc.

Snyder, e. a. (1996). Development and Validation of the State Hope Scale. Journal of Personality and Social Psychology.

Ulfah, M. U. (2014). Gambaran Subjective Well-Being pada Wanita Involuntary Childless. Jurnal Penelitian Psikologi, 02. 